\title{
Usuários da informação com deficiência em bibliotecas: uma análise da produção científica em Biblioteconomia e Ciência da Informação
}

\author{
Danielle Silva Pinheiro Wellichan \\ Doutoranda; Universidade Estadual Paulista, Marília, SP, Brasil; \\ dany_unesp@yahoo.com.br \\ Eduardo José Manzini \\ Doutor; Universidade Estadual Paulista, Marília, SP, Brasil; \\ eduardo.manzini@unesp.br
}

\begin{abstract}
Resumo: Os usuários com deficiência ainda são incógnitas e trazem desafios importantes para a prática bibliotecária. Por isso, analisar a existência deste usuário no contexto da informação é uma necessidade para repensar a atualidade nos ambientes informacionais. Assim, com o objetivo de analisar como a pessoa com deficiência, enquanto usuária da informação, foi abordada pela literatura da área no período de 1970 até 2019, buscou-se realizar um levantamento bibliográfico em uma base de dados da área da Ciência da Informação. Descritores específicos foram utilizados e os resultados analisados e categorizados, considerando variáveis como estudos voltados: 1) à acessibilidade e inclusão; 2) à Tecnologia Assistiva em bibliotecas; 3) às deficiências mais e menos abordadas; 4) aos aspectos relacionados à atuação profissional; 5) às práticas inclusivas existentes nas bibliotecas. Embora a literatura apresente estudos significativos e que as bibliotecas possuam, em sua maioria, recursos de Tecnologia Assistiva, a área requer atenção, reflexão e ação diante das reais necessidades de um usuário com deficiência, para uma atuação mais significativa, que garanta sua inclusão no ambiente informacional.
\end{abstract}

Palavras-chave: Usuário de informação. Pessoas com deficiência. Tecnologia Assistiva. Acessibilidade. Bibliotecas.

\section{Introdução}

A democratização do acesso à informação envolve variáveis que estão além de sistemas relacionados aos processos técnicos da informação. Essas variáveis envolvem aspectos sociais, culturais e econômicos inerentes ao ser humano, portanto, relacionadas à questão de seu compartilhamento e disponibilização. Cunha (1999), por exemplo, apresentou um panorama histórico das bibliotecas, dividido em quatro momentos importantes para o cenário informacional, que ficaram conhecidos como: era tradicional moderna; era automatizada; era eletrônica; e, posteriormente, a era 
digital e virtual. Discorreu sobre a sociedade da informação e do conhecimento e o quanto ela traria de impactos sociais, culturais e econômicos, além de considerar a informação como um recurso estratégico que poderia agregar valor e ser vista como um elemento de competição política e econômica entre os países. De fato, esses impactos aconteceram e a informação tornou-se recurso estratégico, porém não para todos.

Se "quem tem informação, tem poder", como diz o ditado popular, talvez esteja aí uma hipótese sobre o porquê de alguns grupos não conseguirem garantir seus direitos para serem vistos pela sociedade como cidadãos com possibilidades, deveres e oportunidades como quaisquer outros. E não se trata de uma minoria, quando se refere a $24 \%$ da população brasileira com algum tipo de deficiência (IBGE, 2010).

Em diversos segmentos da sociedade, as pessoas com deficiência vivem à deriva, na busca por oportunidades de estudo, trabalho, lazer, cultura e respeito. $\mathrm{Na}$ área da Educação, o cenário é mais desenvolvido, afinal já se somam dez anos da Política de Educação Especial na Perspectiva da Educação Inclusiva (MANZINI; GERMANO; OLIVEIRA, 2018), e, em comparação as outras áreas, não se pode negar o quanto já houve de conquistas, tendo em vista as legislações criadas e estabelecidas ao longo dos anos, mas ainda há muito que se caminhar em busca da equidade de direitos e oportunidades.

$\mathrm{Na}$ Ciência da Informação, área que abriga três campos do conhecimento (ARAÚJO, 2014) - Arquivologia, Biblioteconomia e Museologia -, o usuário da informação com deficiência ainda representa um desafio a ser compreendido. Embora existam opções para acervo e softwares especializados, além dos equipamentos e recursos de Tecnologia Assistiva presentes em grande parte dos arquivos, bibliotecas e museus na atualidade, ele ainda enfrenta um ambiente nem sempre favorável. $\mathrm{O}$ atendimento em si pode ser a primeira barreira a ser enfrentada, pois algumas deficiências exigem mais do que recursos ou tecnologia, como uma comunicação ou organização diferenciada.

Uma biblioteca inclusiva, conforme diretrizes da ALA (2017, p. 1), pode ser um espaço para as pessoas com deficiência ao incluir "[...] tecnologias que proporcionam acesso à comunicação e informação, com materiais que podem ser acessados facilmente", além do incentivo criado por interações e experiências 
acolhedoras e positivas.

Por meio das interações necessárias, reafirma-se que a barreira atitudinal é o ponto inicial entre o usuário com deficiência e a equipe da biblioteca, e dessa relação depende todo o resto, o que pode comprometer, inclusive, a frequência ou o comportamento desse usuário no ambiente informacional. No entanto, não raramente o que falta é capacitação para atender e trabalhar com usuários de grupos específicos, como idosos, crianças com transtornos ou deficiências (independente da faixa etária).

Independentemente das questões que envolvem a empatia, a capacitação profissional precisa ser objeto de atenção para qualquer ambiente. Nas bibliotecas, ao longo dos anos, verifica-se que o usuário com deficiência é fruto de estudos ainda reduzidos, como citam Silva, Santos e Rodrigues (2017) e Coneglian e Casarin (2014). As capacitações, de forma geral, só acontecem em momentos de

[...] emergência ou esporádicas e são oferecidas de forma temporal, o que condiciona as adaptações ou a aquisição de tecnologia a questão de verbas, projetos e financiamentos que nem sempre estão disponíveis [...] (WELLICHAN; MANZINI, 2018, p. 85).

No contexto citado, embora existam leis que busquem oportunizar e garantir melhores condições para a qualidade de vida para as pessoas com deficiência, a exclusão delas acontece ainda quase de maneira natural. A construção civil, em sua maioria, ainda não considera como deveria as questões de acessibilidade em suas obras. As bibliotecas, assim como arquivos e museus, são disponibilizadas em ambientes exclusivos desde seu início, e, como solução pelo menos no aspecto físico, existe a adaptação, a reforma ou até uma nova construção, porém nem sempre são modificações possíveis ou atendem a pessoa com deficiência em suas necessidades, respeitando sua independência e autonomia. Outra situação, bem comum nesses três locais de busca pela informação, é a falta de espaço devido ao crescimento de seus acervos, diminuindo, consequentemente, o espaço para circulação e convivência.

Programas e serviços podem contribuir para um cenário mais inclusivo, porém precisam estar associados à capacitação dos recursos humanos de profissionais e do próprio público local, com ou sem deficiência, e que sejam de forma constante, pois podem ficar desatualizados ou ser esquecidos facilmente.

Nas bibliotecas, especificamente, a literatura indica a necessidade de olhar 
para o usuário desde o início, para planejar seu espaço, adequar suas políticas e sistemas, desenvolver e disponibilizar suas coleções, produtos e serviços. No entanto, nem sempre isso acontece, pois questões como as discutidas anteriormente dificultam o acesso inicial e a acessibilidade de alguns usuários, como os que possuem deficiência, mobilidade reduzida (sejam elas permanentes ou temporárias), gestantes e idosos.

Frequentemente confundidos na literatura e no cotidiano em sociedade, acesso e acessibilidade não são sinônimos. Segundo Manzini (2005, p. 31), o acesso “[...] parece estar também relacionado à questão da atitude em relação à exclusão. Já o termo acessibilidade parece refletir algo mais concreto, palpável”. A definição do termo acessibilidade foi modificada e ampliada pela Lei n. 13.146 como "[...] condição para utilização, com segurança e autonomia, total ou assistida, dos espaços, mobiliários e equipamentos urbanos, das edificações, dos serviços de transporte e dos dispositivos, sistemas e meios de comunicação e informação [...]" para pessoas com deficiência ou com mobilidade reduzida (BRASIL, 2015, não paginado).

A acessibilidade de fato diminui a desvantagem, mas não garante a oportunidade. Recursos humanos, físicos e materiais são elementos de um conjunto necessário para que práticas, produtos e serviços sejam criados e disponibilizados para todo tipo de necessidade que uma pessoa possa ter, e, quando o usuário é real ou potencial, são decisórios para o seu acesso e sua acessibilidade em uma biblioteca. Diante disso, questiona-se: o que a literatura especializada possui sobre a pessoa com deficiência, nas bibliotecas? Quais as melhores práticas descritas pelos autores da área para a atuação dos profissionais? Quais as orientações para um atendimento inclusivo em uma biblioteca? $\mathrm{O}$ acesso e a acessibilidade existem ou não nas bibliotecas? E os recursos e equipamentos da Tecnologia Assistiva, estão presentes? De que forma podem contribuir para a inclusão de um usuário com deficiência em uma biblioteca?

Com o objetivo de analisar como a pessoa com deficiência, enquanto usuária da informação, foi abordada pela literatura da área e analisar as questões anteriormente citadas, foi proposta a realização de um levantamento bibliográfico em uma base de dados da área da Ciência da Informação, no período de 1970 até 2019. 


\section{Método}

O levantamento bibliográfico proposto e realizado neste artigo foi desenvolvido no primeiro semestre de 2020. Considerou a produção científica na área da Ciência da Informação, desde os anos de 1970, período inicial estabelecido pela base selecionada para o presente estudo. Pesquisou-se o que foi produzido na área da Biblioteconomia referente à questão do usuário da informação com deficiência e sua acessibilidade em ambientes informacionais, publicados até o ano de 2020 (recorte temporal adotado de 1970-2019).

Foram excluídas as publicações que apresentaram duplicidade e os registros sobre a acessibilidade na web, por não corresponderem ao objetivo inicialmente proposto no presente artigo, mas não foram descartados para uma análise futura devido sua importância no contexto geral dos usuários com deficiência. O processo de verificação dos registros localizados foi dividido em três etapas, conforme descrito a seguir (Figura 1).

Figura 1 - Etapas do levantamento bibliográfico.

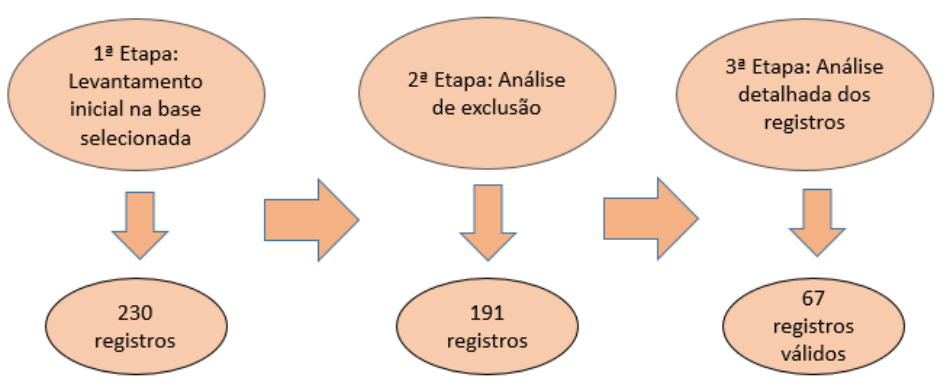

Fonte: Elaborada pelos autores (2020).

$\mathrm{Na}$ primeira etapa, utilizaram-se os descritores selecionados e obtiveram-se 230 registros recuperados. Para a segunda etapa, na análise de exclusão, materiais em duplicidade foram descartados mediante análise do título, resumo e palavras-chave no próprio documento em formato PDF, chegando a 191 registros. Para finalizar, na terceira etapa, análise detalhada dos registros, que contemplou a leitura do registro na íntegra e trouxe o total de 67 artigos de grande significância para a temática proposta.

A partir daí as publicações foram analisadas e, de acordo com a técnica de análise de Bardin (2016), organizadas em categorias temáticas conforme suas 
particularidades para melhor visualização dos trabalhos desenvolvidos. Para a autora, “[...] classificar os elementos em categorias impõe a investigação do que cada um deles tem em comum com os outros. O que vai permitir o seu agrupamento é a parte comum existente entre eles." (BARDIN, 2016, p. 148).

Desta forma, embora todos os registros selecionados sejam a respeito da pessoa com deficiência enquanto usuária da informação, cada abordagem possui uma particularidade, que foi agrupada em determinada categoria. Mesmo diante de registros que aparentaram tratar de mais de um assunto dentro da proposta em questão, o que prevaleceu foi a interpretação do conteúdo de maneira geral.

Diante disto, as categorias definidas foram: (a) acessibilidade e inclusão; (b) Tecnologia Assistiva em bibliotecas; (c) deficiências mais citadas; (d) deficiências menos citadas na literatura; (e) aspectos sobre a atuação profissional; e, (f) práticas inclusivas.

\section{Resultados e discussão ${ }^{1}$}

A base de dados selecionada para este estudo foi a Base de Dados Referencial de Artigos de Periódicos em Ciência da Informação (BRAPCI), que tem como cobertura temática a Biblioteconomia e a Arquivologia, cujo objetivo é “[...] subsidiar estudos e propostas na área de Ciência da Informação, fundamentando-se em atividades planejadas institucionalmente." (BUFREM, et al., 2010, p. 25). Para isso, foram identificados na área da Ciência da Informação (CI) títulos de periódicos, indexando seus artigos e se tornando uma base referencial que abriga a Biblioteconomia e a Arquivologia, desde os anos de 1970.

De acesso público, a BRAPCI disponibiliza, em sua página, referências, resumos de periódicos ativos e descontinuados, além do arquivo da obra para acesso ao documento original, por meio de busca simples ou avançada nas opções de título, palavras-chave e resumo, ou autores, título, palavras-chave, resumo e texto completo.

Para este estudo, após as etapas realizadas, chegou-se a 67 registros, conforme descrito na Tabela 1: 
Tabela 1 - Registros selecionados e suas categorias.

\begin{tabular}{ll}
\hline \multicolumn{1}{c}{ CATEGORIA } & REGISTROS \\
\hline Acessibilidade e Inclusão & 16 \\
Tecnologia Assistiva em bibliotecas & 12 \\
Deficiências mais citadas & 25 \\
Deficiências menos citadas & 03 \\
Atuação Profissional & 06 \\
Práticas Inclusivas & 05 \\
\hline Total & $\mathbf{6 7}$ \\
\hline
\end{tabular}

Fonte: Elaborado pelos autores (2020).

Nos aspectos metodológicos, verificou-se o predomínio de estudos bibliográficos, seguidos de documentais e de campo, realizados por meio de relatos de experiência, grupos focais, uso de questionários e realização de entrevistas.

De forma geral, os conteúdos dos estudos contemplaram questões de: (a) atendimento; Tecnologia Assistiva em bibliotecas; (b) observação direta do ambiente existente, no tocante às questões de acesso e acessibilidade; (c) barreiras existentes; (d) adequação de acervos; (e) verificação do cumprimento da NBR 9050; (f) projetos de adequação para bibliotecas; (g) espaços acessíveis; (h) propostas inclusivas; (i) comunicação visual em bibliotecas; (j) discussões sobre teorias para acessibilidade; (k) a biblioteca no contexto histórico; (1) percepção e satisfação de usuários em bibliotecas; (m) levantamento de dificuldades enfrentadas pelos usuários com deficiência, em bibliotecas. Percebe-se, de forma imediata, que o usuário com deficiência, embora sempre tenha existido, assim como as próprias bibliotecas, ainda não despertou atenção suficiente para os estudos da área. E para essa falta de interação, há fatores que podem estar relacionados às questões da formação e capacitação para tal. No entanto, há também que se considerar fatores como: o desconhecimento a respeito do usuário e suas necessidades; desatualização prática, no que se refere aos recursos e tecnologias disponíveis; falta de investimentos institucionais; e a hipótese de que ações realizadas não sejam registradas ou comunicadas cientificamente, tendo em vista a dinâmica da vida do profissional.

O fato é que há de se despertar para a situação, pois é longa a caminhada a ser percorrida, como mostram as categorias a seguir, organizadas com a finalidade de descrever sobre as principais ideias abordadas pelos autores estudados. 


\subsection{A acessibilidade e a inclusão}

As bibliotecas estão relacionadas à coletividade, à memória social e cultural e são indispensáveis à construção da identidade e da história das sociedades, pois representam compromissos de ordem político-social que se referem à conservação e manutenção de acervos “[...] correspondentes à fortuna crítica, teórica e literária de uma sociedade, mas também ligados à distribuição de saberes e partilha do patrimônio cultural com seu público.” (MIRANDA, 2019, p. 299).

Diante de sua importância, também representa a democratização dos saberes na busca por se tornar um espaço para todos. Mas, em virtude de fatores diversos, as bibliotecas e as pessoas com deficiência encontram-se distanciadas, ou em uma relação superficial, e o fato de ter o que oferecer não pode ser mais importante do que saber para quem ou como oferecer.

Milanesi (2013) comenta sobre dois momentos vivenciados pelas bibliotecas, que podem exemplificar alguns questionamentos que permeiam essa relação. $O$ primeiro momento remete ao século XIX, quando há recursos conhecidos que podem ser acessíveis (se bem aproveitados); e o segundo momento, no século XXI, quando, mesmo com as disponibilidades anteriores, é preciso tomar decisões que ultrapassam o campo técnico. A situação referente ao usuário é um dos assuntos que ultrapassam o campo técnico e exigem decisões que contribuam para o pertencimento deles em uma biblioteca. Afinal, a preocupação com a inclusão das pessoas com deficiência e a acessibilidade no ambiente existe nos estudos da Biblioteconomia, mas, embora sejam questões discutidas, ainda não estão bem esclarecidas.

Trata-se de um esclarecimento que falta para as áreas de atuação de maneira geral, pois, mesmo em meio a campanhas conscientizadoras e relatos de experiência mais frequentes do que há algumas décadas, a pessoa com deficiência ainda é tratada de forma generalizada: é pouco conhecida ou é tratada de forma igual em suas necessidades, o que acaba por mantê-la ainda distante do ambiente e dos profissionais.

Sobre essa diversidade na deficiência, Carvalho e Almeida (2012) afirmam que, ao contrário de outros grupos sociais visivelmente homogêneos, as pessoas com deficiência possuem em sua diversidade a sua característica mais evidente, portanto, não podem ser vistas em suas necessidades como iguais. Compreender as diferenças 
pode possibilitar aos profissionais um direcionamento de serviços específicos que atendam às deficiências de forma mais pontual.

Quanto à acessibilidade, quando é estudada, o termo é tratado de forma ampla e, frequentemente, está associado à questão física. No entanto, a acessibilidade não pode ser considerada apenas pelos aspectos físicos, pois há outras barreiras que também completam o sentido da palavra. A literatura já menciona, há anos, a questão da acessibilidade comunicativa, por exemplo. Existem ainda outras barreiras que necessitam ser trabalhadas, como a das atitudes sociais desfavoráveis à inclusão, que são fundamentais para o acolhimento da pessoa com deficiência na biblioteca (MANZINI, 2014).

Em alguns registros localizados para este estudo, os autores referem-se à acessibilidade como algo relacionado à legislação, outros a relacionam a recursos ou ao espaço físico nas bibliotecas. Conforme citado no estudo de Vianna e Pinto (2017), que buscou identificar elementos bibliométricos no Campo da Ciência da Informação em associação aos termos "deficiência, acessibilidade e tecnologia assistiva", o referencial da área se encontra disperso e escasso, mas apresenta possibilidades importantes para se desenvolver.

Santos e Carvalho (2020, p. 6) descrevem a acessibilidade como "[...] a construção de produtos, ambientes e serviços de forma a permitir sua utilização por todas as pessoas de maneira autônoma e segura." Fialho e Silva (2012) complementam a definição ao afirmar que a acessibilidade possibilita romper barreiras, e diante disso, a biblioteca precisa adequar seu espaço físico e a capacitação de colaboradores na prestação dos serviços.

Comumente confundidas, o acesso e a acessibilidade possuem diferenças conceituais importantes: enquanto o acesso reflete um desejo de mudança, um processo ou a busca por um objetivo, a acessibilidade está relacionada a uma necessidade concreta, como algo que pode ser observado, implementado, possível de medição e avaliação. "Dessa forma, podem-se criar condições de acessibilidade para que as pessoas possam ter acesso a determinadas situações ou lugares.” (MANZINI, 2005, p. 32).

A pessoa com deficiência tem seus direitos defendidos por meio de políticas públicas inclusivas, que não se restringem apenas à educação, mas se estendem por 
todos os segmentos da sociedade (MAIOR, 2017). Nas bibliotecas escolares ou nas universitárias, a implantação de políticas públicas de inclusão deve seguir as reformas educacionais iniciadas na década de 1990 e demais marcos históricos que defendem os direitos e a inclusão da pessoa com deficiência.

Com a expansão da área da Tecnologia Assistiva e a legislação que defende a inclusão, as bibliotecas conseguiram melhores condições para compor seus acervos especiais e elaborar serviços específicos com o apoio de softwares e recursos variados, conforme descritos a seguir.

\subsection{A Tecnologia Assistiva nas bibliotecas}

$\mathrm{O}$ atendimento à pessoa com deficiência em bibliotecas universitárias, para ser considerado inclusivo, precisa seguir princípios, orientações e diretrizes como as citadas por Costa e Duarte (2017) e Assis e Diniz (2017). Segundo os autores, é assim que se podem evitar principalmente as barreiras atitudinais. Para que isso aconteça, as autoras destacam a importância de o profissional estar disposto a removê-las, aprimorando suas competências e tendo recursos de Tecnologia Assistiva à disposição.

A área da Tecnologia Assistiva (TA) abrange um grupo de serviços, produtos e ferramentas desenvolvidos por meio da tecnologia, para facilitar atividades cotidianas de pessoas com deficiência e garantir-lhes autonomia, independência e qualidade de vida (BERSCH, 2013; FERNANDES; VIANNA, 2016; MATOS; LEMOS; SILVA, 2017; MELO; COSTA; SOARES, 2006; SANTOS; CARVALHO, 2020), porém requer primeiramente um profissional capacitado para otimizar o uso dela na biblioteca.

A capacitação citada refere-se não só ao profissional, que deve saber sobre conceitos e práticas para produção de produtos e serviços, mas também para ensinar ao usuário quando solicitado, e, para isso, ele precisa conhecer e saber como utilizar.

Oliveira e Silva (2015) consideram os recursos e os equipamentos da Tecnologia Assistiva uma necessidade permanente. Segundo as autoras, associados a eles, as atitudes/práticas, a compreensão e o designer universal são fatores que podem contribuir para o desenvolvimento de uma sociedade para todos, desde que o bibliotecário esteja capacitado e trabalhe em conjunto com outros profissionais, de 
forma que as atuações representem importantes parcerias para o atendimento, o aprendizado e o conhecimento ali gerado e compartilhado.

Livros em Braille ou em áudio, scanner de voz, lupa eletrônica, teclado colméia, computadores adaptados com sintetizador de voz e conversor de texto em áudio, ampliadores ou ledores de tela, aplicativos de acessibilidade para tablets, máquina Perkins, bengalas, punções e regletes, sorobans, impressora Braille, são exemplos de tecnologias disponíveis em bibliotecas, criadas para propiciar condições para a acessibilidade. Baseados nestes recursos, os produtos e serviços - exposições permanentes; incentivos à leitura; capacitações sobre os equipamentos de TA por meio de projetos comunitários; composição de acervos adaptados; gravação de livros falados com a utilização do scanner de voz; e atividades de integração por meio de jogos, eventos, atividades culturais ou brinquedos acessíveis - são demonstrativos de ações inclusivas resultantes da TA em bibliotecas (BONILHA; CARRASCO, 2008; FERREIRA, 2008; FERREIRA et al., 2012; FIALHO; SILVA, 2012; LEMOS; SILVA, 2017; ORRICO; SILVA, 2014; PINHEIRO; OLIVEIRA, 2018; PINTO, 2006; SOUZA; MANOEL, 2008; TABOSA; PEREIRA, 2013).

Os recursos e equipamentos não são desconhecidos, estão presentes na maioria das bibliotecas da atualidade. Porém, estratégias de utilização, serviços e/ou produtos criados considerando o uso deles são pouco citados. Questiona-se então: o bibliotecário tem utilizado tais recursos de forma a extrair sua funcionalidade real? É possível acreditar que a mera presença deles no ambiente informacional represente possibilidades para a inclusão de um usuário com deficiência? Surge deste questionamento a importância e a necessidade da divulgação e do compartilhamento de práticas e ações, a fim de que estas possam servir de subsídios teóricos e práticos para outros profissionais.

Conforme Wellichan e Manzini (2018), não basta "ter" o recurso, é preciso saber como utilizá-lo. Assim, ressaltaram a importância de compreender os recursos e equipamentos da Tecnologia Assistiva para oferecer produtos e serviços significativos aos usuários com deficiência. Além disso, o estabelecimento de parcerias, elaboração de projetos, capacitação profissional, captação de recursos e investimentos, divulgação e compartilhamento de ações realizadas podem trazer resultados satisfatórios para o ambiente receber e manter um usuário que apresente 
alguma deficiência.

\subsection{As deficiências mais abordadas}

Entre as deficiências encontradas nos registros, a deficiência visual (cegueira e/ou baixa visão) foi a mais citada, seguida da Deficiência Auditiva e da Deficiência Física. Também foram encontrados estudos sobre a Deficiência Intelectual, Surdocegueira e Transtorno do Espectro Autista (TEA), porém com menos freqüência.

\section{a) Deficiência visual}

Pupo, Carvalho e Oliveira (2008) descrevem as atividades realizadas sob demandas, produzidas para usuários com deficiência sensorial e física no Laboratório de Acessibilidade na Biblioteca Central César Lattes, na Universidade Estadual de Campinas (UNICAMP). De acordo com o cronograma e as bibliografias utilizadas nas disciplinas cursadas pelos alunos com deficiência, na biblioteca, verificam a existência dos materiais on-line, caso não existam, digitalizam, organizam e enviam por e-mail para que o aluno possa realizar a leitura com o auxílio de leitores de tela.

Com suas semelhanças, a implantação do Serviço de Inclusão e Acessibilidade à Informação na Rede de Bibliotecas da UNESP, em 2013, foi descrita por Ottoni et al. (2014) e Storti et al. (2014). Nesse serviço, recursos de Tecnologia Assistiva (leitores autônomos, scanner leitor portátil, lupa eletrônica, linha Braille e software leitor de tela) são disponibilizados na biblioteca do projeto piloto e em mais seis unidades (Araraquara, Assis, Bauru, Franca, Ilha Solteira e Presidente Prudente).

Segundo os autores, a capacitação da equipe foi dividida em duas etapas: a primeira foi ofertada por um docente da UNESP, que trabalhou a conscientização dos colaboradores a respeito das deficiências e da importância dos atendimentos prioritários, utilizando intervenções e simulações de atendimentos aos alunos com deficiência; e, na segunda etapa, foi realizado um treinamento técnico de uso das tecnologias, promovido por um integrante do grupo que tem deficiencia visual.

Ainda no ambiente universitário, Pinheiro, Silva e Rodrigues (2008) relatam as barreiras arquitetônicas e acadêmicas de alunos com deficiência visual, na Universidade Federal do Mato Grosso. Barreiras arquitetônicas - como calçadas mal construídas ou danificadas, postes e orelhões em locais inadequados, falta de 
sinalização e de piso antiderrapante em banheiros e salas de aula, laboratórios com degraus e rampas não apropriados e a falta de preparação dos professores da universidade - foram apontadas no estudo. Na biblioteca, a barreira estava no acesso aos materiais e, diante disso, propôs-se um projeto de extensão para o desenvolvimento de uma audioteca. Tais barreiras internas e externas também foram relatadas no estudo de Diniz, et al. (2017a) em uma biblioteca escolar, no Instituto Federal do Rio de Janeiro, e por Guerreiro et al. (2015), na biblioteca do Instituto Federal do Amazonas.

O desenvolvimento de projetos que integram comunidade e a pessoa com deficiência está presente também no estudo de Moraes (2008, p. 254). O autor relata o processo de implantação do Projeto Espaço Braille, considerado um centro de informação, formação, cultura e lazer para pessoas com deficiência visual, em uma biblioteca pública de São Carlos, SP. Segundo o relato, o projeto possui “[...] três grandes linhas de ação - a informação e a leitura; a mobilidade e a independência e a educação para o trabalho.", a fimm de oferecer cursos de capacitação e treinamentos específicos para esse público.

Ávila et al. (2014) também descrevem a experiência de ações desenvolvidas em uma biblioteca pública na Bahia, que possui quatro décadas de experiência com acessibilidade para pessoas com deficiência visual e serviços que buscam envolver a comunidade nas ações internas. O setor conta com o apoio de equipamentos de Tecnologias Assistivas, como software de voz, linha Braille, lupas e scanner.

Costa e Silva (2019) fizeram uma pesquisa com alunos com deficiência visual, na Seção Braille da Biblioteca Central da Universidade Federal da Paraíba (UFPB), e constataram carências quanto ao acervo, ao acesso ao local e aos serviços oferecidos.

Ramalho, Hamad e Guimarães (2016) descrevem o comportamento informacional de estudantes com deficiência visual, na universidade. Constataram que medidas preventivas, corretivas e assistivas precisam ser colocadas em prática, pois as necessidades mais básicas de um universitário envolvem diretamente as atividades acadêmicas, como seminários, provas e produção científica, e para isso precisam de fontes de informação disponíveis e acessíveis.

Malheiros e Cunha (2018) resgatam marcos históricos das pessoas com deficiência visual, nas bibliotecas, no contexto brasileiro e no exterior, além de 
descrever recursos de Tecnologia Assistiva que podem auxiliar no atendimento especializado.

Ainda sobre usuários com deficiência visual, mas com uma abordagem mais técnica e biblioteconômica, Rodrigues, Fujita e Dal'Evedove (2017) abordam a política de indexação para bibliotecas públicas e universitárias no tocante às questões de acessibilidade e da inclusão ao destacar a dificuldade em organizar processos e condutas da atividade de indexação para esses usuários. Essa preocupação é necessária para a Biblioteconomia, pois vai definir e influenciar no tratamento dos documentos, os princípios, métodos, orientações e efeitos na recuperação da informação (LEIVA; FUJITA, 2012).

\section{b) Deficiência auditiva}

A deficiência auditiva e a surdez possuem estudos realizados por Miranda e Miranda (2015), que analisaram o sistema de bibliotecas de uma universidade no estado do Rio de Janeiro e, posteriormente, também por Miranda (2017), que apontou a sinalização como melhoria na biblioteca.

Recentemente, Miranda, Costa e Silva (2019) partiram do diagnóstico realizado no estudo de 2015 e relataram as ações que foram realizadas após os apontados no estudo inicial. Constataram que, embora tenham sido encontradas poucas alterações, algumas medidas estão em andamento.

Para Vieira (2014), o atendimento de usuários com deficiência auditiva exige alguns cuidados, como chamar a atenção dele, falar devagar e de frente, evitar objetos ou gestos na frente dos lábios, além da necessidade de se qualificar para o uso da Libras. Ao oferecer serviços com esses cuidados, as bibliotecas estarão contribuindo para formações profissionais mais competentes (FERREIRA; CHAGAS, 2016).

Acessibilidade para surdos e medidas de integração são apontadas por Migliori e Santos (2017) no Instituto Nacional de Educação de Surdos. Além de descrever sobre a experiência dos usuários surdos na biblioteca, as autoras trazem informações sobre o acervo acessível e apresentam orientações quanto ao atendimento de pessoas surdas, baseadas nas diretrizes estabelecidas pela Federação Internacional de Associações e Instituições Bibliotecárias (IFLA) (2000). Tais diretrizes se aplicam em todos os tipos de bibliotecas, não contem prescrições quantitativas e se destinam a servir como critérios para serviços específicos para pessoas surdas (MIGLIOLI; 
SANTOS, 2017).

Dias e Bon (2019, p. 85) descrevem o atendimento de um universitário na biblioteca central da Universidade Federal do Rio Grande do Norte, discutindo sobre legislação, orientações e políticas adotadas pela universidade. As autoras afirmam que, devido à postura de intermediário que o bibliotecário assume entre a informação e o usuário, o bibliotecário "[...] deve minimamente estar habilitado a comunicar-se através da Língua Brasileira dos Sinais (LIBRAS), que é a língua usada pela comunidade surda." e discutem a formação no curso de graduação em Biblioteconomia, que não oferece a disciplina como obrigatória e sim optativa, realidade que se repete nos cursos vigentes no país.

\section{c) Deficiência física}

Para a Deficiência Física, autoras como Giacumuzzi, Moro (2014) e Jacinto (2008) defendem que é responsabilidade do bibliotecário tornar o ambiente acessível e permitir o acesso à informação independente de qual seja a limitação do usuário. Tratam da necessidade de piso firme (não escorregadio), banheiros e bebedouros adaptados segundo a NBR 9050, balcão de empréstimo mais baixo, mobiliário adequado e cuidados especiais com ambientes que ofereçam tapetes, capachos, desníveis, degraus, corrimão, escadas, computadores e terminais de consulta, além das próprias estantes (largura e disponibilização de materiais).

Roma e Cavalcante (2018) também apresentam a importância da acessibilidade nas bibliotecas escolares de escolas estaduais de Londrina, e apontam dificuldades encontradas no ambiente apresentadas aos gestores escolares, como: bibliotecas localizadas no segundo andar do prédio; a ausência de rampas e elevadores; estantes com largura insuficiente para a passagem de cadeiras de rodas; e falta de profissional capacitado para atuação significativa no local.

Cavalcante, Garcia e Rados (2015) constatam que, embora os equipamentos e mobiliários disponíveis na biblioteca atendam aos usuários, há dificuldade com a acessibilidade arquitetônica, com a inexistência de rampas ou elevadores. Em alguns estudos, o cenário da biblioteca se apresenta acessível para uma deficiência e não para outra, como no estudo de Sampaio (2014).

Ao longo dos anos, as bibliotecas conseguiram mudanças em sua estrutura, seja por novas construções, seja por adaptações necessárias. Mas, paralelamente, 
ainda existem bibliotecas que mal possuem espaço para seus acervos, o que acaba comprometendo medidas e recomendações estabelecidas pelas normas brasileiras de acessibilidade.

O usuário que possui alguma limitação física ou mobilidade reduzida, seja ele usuário de cadeira de rodas, muleta ou bengala, vai exigir um ambiente em que possa frequentar e circular com segurança, autonomia e independência. Por isso, cuidados na iluminação, disponibilização de rampas, elevadores, espaço de rotação e circulação entre as estantes e os locais de trânsito e convivência, banheiros e mobiliários adaptados são fundamentais para uma biblioteca em termos estruturais. Além do espaço interno, há o entorno da biblioteca que também precisa seguir os padrões de acessibilidade e deve fazer parte das preocupações e do planejamento de um ambiente acessível.

\subsection{Outras abordagens importantes}

A identificação de como a Tecnologia Assistiva contribui para o processo de aprendizagem de crianças com Deficiência Intelectual foi estudada por Ventura, Vianna e Bedin (2017, p. 17), que recomendam:

[...] é necessário estudar os alunos para estabelecer suas necessidades e indicar os recursos de TA necessários. E tal constatação se estende a todo tipo de atendimento associado à escola, tal como bibliotecas, arquivos e museus.

O estudo não trata das bibliotecas especificamente, mas apresenta de forma breve aspectos que podem ser adaptados e desenvolvidos no ambiente.

Outra abordagem sem maiores estudos é sobre a surdocegueira (quando a pessoa é acometida pela cegueira e pela surdez), que foi discutida por Santos, Diniz e Rangni (2017, p. 2060): “[...] ações devem ser planejadas com os profissionais da biblioteca, antecipando-se nas buscas de soluções à problemática, ou seja, de se verem diante de uma barreira comunicacional com um usuário surdo-cego." Para isso, os profissionais precisam desenvolver competências e capacitação adequada.

Especificamente sobre usuários da informação com Transtorno do Espectro Autista (TEA), os autores Santos, Diniz e Fernandes (2017) afirmam que o bibliotecário precisa estar primeiramente sensibilizado para a necessidade de se 
capacitar para atender a todo tipo de usuário. Estratégias adequadas serão necessárias para eventuais situações, ocasionadas pela falta de habilidade social do usuário envolvido. $\mathrm{O}$ estudo se torna de extrema importância tendo em vista a estimativa de que, a cada grupo de 160 crianças em todo o mundo, existe uma com diagnóstico do TEA, de acordo com dados da Organização Mundial de Saúde (OMS, 2017), o que não apresenta garantias de que algum profissional ou instituição possa passar indiferente diante de tal fato.

\footnotetext{
Conhecer o usuário autista e disponibilizar atividades biblioteconômicas e pedagógicas é fundamental para interação e participação do aluno na construção do conhecimento. Para isso, busca-se levantar quantos as suas dificuldades e trabalhar suas potencialidades, respeitando sua singularidade (SANTOS; DINIZ; FERNANDES, 2017, p. 1873).
}

Por causa das suas especificidades, um indivíduo com TEA, geralmente, pode não ser percebido facilmente em uma biblioteca, mas, como afirmado pelos autores citados e por Wellichan e Lino (2018), há algumas recomendações básicas que podem ser trabalhadas, como: (a) a comunicação visual consciente (uso de imagens e sinalização pelo ambiente); (b) a organização do local sem mudanças repentinas e devidamente comunicadas; (c) o espaço ambiental "limpo" (ou seja, sem poluição visual ou material); (d) o cuidado com eventos que possam apresentar "barulhos" ou trazer alguma desordem ao ambiente. Identificar as demandas informacionais, disponibilizar materiais variáveis e contar com o contato de familiares e profissionais especializados (FARMER, 2013) também são ações inclusivas para usuários com TEA.

Além disso, em uma instituição de ensino (desde as primeiras fases escolares até o ensino superior), no ato da vinculação acadêmica, a pessoa com deficiência deve ser identificada, e a partir daí setores locais devem ser informados sobre a necessidade de serviços especiais (WELLICHAN; SOUSA, 2017). Porém, partindo do princípio de que o acesso e a acessibilidade devem ser princípios iniciais e frequentes, ser inclusivo deve constituir uma preocupação de todo profissional, independentemente de ter ou não usuário da informação com deficiência em sua biblioteca. 


\subsection{Sobre a atuação profissional}

Embora quase todos os registros selecionados para este trabalho tenham trazido apontamentos, mesmo que finais, a respeito da atuação profissional, alguns foram pontuais na questão. Relatos de iniciativas de capacitações, workshops, cursos e minicursos são opções viáveis para a atualização profissional, porém precisam ser constantes, pois tecnologias se atualizam e/ou caem em desuso de forma rápida, impedindo que o bibliotecário cesse sua busca pelo conhecimento.

No cenário profissional, Araújo et al. (2017) referiram-se a um curso de Língua Brasileira de Sinais (Libras) destinado aos colaboradores das bibliotecas e demais interessados da comunidade universitária da Universidade de São Paulo, campus São Carlos, em 2017, com o objetivo de oferecer condições para a comunicação com o aluno surdo.

Após algumas experiências com alunos com deficiência e algumas modificações, em 2016, um colaborador surdo, da equipe de limpeza, foi lotado na biblioteca. Para melhor integrá-lo à equipe e ao ambiente, utilizaram um aplicativo de celular para manterem a comunicação, além de promover palestras e adquirir obras especializadas. Ao final do curso, elaborou-se um vídeo institucional sobre a pessoa surda e sua comunicação.

É evidente que um curso (minicurso) não seria suficiente para estabelecer uma comunicação definitiva e resolver todas as dificuldades que aconteceriam ali, porém “[...] essa realidade serviu de estímulo para o planejamento de ações de integração e capacitação da equipe para que a Biblioteca pudesse antecipar-se à necessidade de futuros alunos surdos que ingressem na universidade" (ARAUJO, et al., 2017, p. 1903).

Outro assunto pouco tratado, mas também importante, é o colaborador com deficiência que foi abordado no estudo de Baptista e Gonçalves (2016) em um sistema de bibliotecas de uma universidade. Trata-se de uma temática pouco estudada na área e, segundo as autoras, além das questões que dificultam o acesso e a acessibilidade para o usuário com deficiência, as bibliotecas também se encontram despreparadas para receber em suas equipes pessoas nessas condições, embora as atividades técnicas e administrativas realizadas no ambiente possam ser realizadas sem problemas maiores, dependendo das condições de cada pessoa. Torna-se 
fundamental analisar os cargos que podem ser oferecidos de acordo com cada perfil profissional a ser contratado (BAPTISTA; GONÇALVES, 2016).

A oportunidade e o acolhimento são necessários para proporcionar a inserção da pessoa com deficiência no mercado de trabalho, para o cumprimento da legislação existente, por isso o bibliotecário gestor precisa conhecer o perfil e as condições funcionais e sociais da pessoa que trabalhar em sua equipe, para favorecer e otimizar os recursos e os investimentos necessários a ela e ao local. Pupo et al. (2008, p. 83) compartilham a necessidade da presença de colaboradores com deficiência, pois "[...] são os primeiros parceiros a quem se deve recorrer, porque sabem das próprias necessidades e constituem o elo entre as partes interessadas no atendimento de qualidade."

Almeida, Furtado e Diniz (2017) citam a importância das parcerias, como a desenvolvida entre os núcleos de acessibilidade e/ou grupos de trabalho para apoiar o estudante com deficiência no ensino superior e as bibliotecas universitárias, e trazem um importante apontamento: 64,7\% dos núcleos de acessibilidade brasileiros e $75 \%$ dos grupos de trabalhos citados não possuem controle sobre o registro de alunos com deficiência que frequentam a biblioteca, o que comprova a falta de parceria entre os envolvidos e compromete também a vida acadêmica do universitário. Essa situação reflete-se no planejamento do ambiente, que vai requerer tempo hábil para que mudanças e adequações sejam avaliadas e oferecidas, se já não existirem no local.

Estudos portugueses também têm contribuído de forma significativa no contexto das bibliotecas: é o caso de Novo (2015), que apresentou o "Projeto Acessibilidades", desenvolvido no segundo semestre de 2012 em 15 bibliotecas do município de Lisboa. Nele, foram identificadas as condições de acessibilidade física, comunicacional, equipamentos e assistência, e demonstrou que, embora o cenário não seja completamente favorável no que diz respeito à acessibilidade, existe um forte empenho nas equipes em atender as pessoas com "diferentes tipos e graus de funcionalidade". Ainda no cenário português, Diniz, Almeida e Furtado (2017b) realizaram uma investigação mista para conhecer práticas inclusivas em bibliotecas universitárias brasileiras e portuguesas e por meio delas identificaram barreiras que interferem na acessibilidade local.

Tabosa e Pereira (2013) relatam que a compreensão sobre o funcionamento 
dos recursos disponíveis na biblioteca e a capacitação de equipes e alunos são pontos importantes para um atendimento inclusivo. Por meio de um estudo realizado com bibliotecários cadastrados no conselho regional da região, investigaram o conhecimento dos profissionais a respeito do que é a Tecnologia Assistiva e citam exemplos: “Apenas 4\% dos respondentes não possuem nenhum entendimento sobre o que é uma tecnologia assistiva. [...] Dos respondentes, 91\% informaram que sabem o que é uma tecnologia assistiva." (TABOSA; PEREIRA, 2013, p. 26). Porém, ao serem questionados sobre exemplos, surgiram contradições, como a confusão entre as Tecnologias Assistivas e a Tecnologia de Informação e Comunicação,

[...] dando, como exemplos: monitores de reconhecimento óptico de caracteres e teclado virtual, que não são tecnologias assistivas, além de terem citado a Língua Brasileira de Sinais (LIBRAS), que é a primeira língua dos surdos e o Braille, que é um sistema de leitura e escrita através do tato. LIBRAS e Braille são considerados tecnologias assistivas, mas não eletrônicas, como mencionado por dois dos nossos respondentes. Outros mencionaram duas interfaces: a microFênix, que é uma ferramenta voltada para pessoas com dificuldades motoras e o Dosvox, que é uma ferramenta voltada para os deficientes visuais terem acesso à informação através do computador, permitindo que seu usuário utilize as ferramentas normais de um computador e navegue pela web (TABOSA; PEREIRA, 2013, p.28).

Além disso, os respondentes apontaram que algumas instituições não veem justificativa para ter tais recursos, uma vez que não há alunos dessa natureza; se houver, ou quando houver, podem providenciar. Mas como providenciar algo quando a situação já está em andamento? Aguardar a situação acontecer para então agir já foi citada há alguns anos como uma alternativa inviável (OMOTE, 2004², apud PINHEIRO, 2004, p.74),

Deve-se pensar em função de todo e qualquer possível usuário e ao falar em acessibilidade e inclusão, a gente não pode nem pensar em contabilizar custo e benefício, ainda que um único usuário venha fazer uso de um determinado recurso, este deve estar presente. Do contrário, não há razão e não se justifica toda essa defesa que se faz apaixonadamente no sentido de igualdade de direito etc. Não importa se é um só usuário, ou se são 50, 200, 400, desde que haja uma única pessoa, seu direito de ter acesso à informação tem que ser assegurado.

Esse direito à informação está previsto na legislação, e os bibliotecários, em sua maioria, reconhecem a necessidade de atuação mais efetiva diante dos usuários e 
de oferecer condições para que exista ao menos uma inserção da pessoa com deficiência no local, mesmo diante de questões que esbarrem na política institucional ou no orçamento local.

Há, ainda, desconhecimento tanto sobre a pessoa com deficiência quanto aos recursos, produtos e serviços que lhe podem ser oferecidos, o que comprova a necessidade de capacitação e atualização do profissional. Dessa forma, parcerias, inovação e criatividade se tornam pilares de mudanças e propostas viáveis para constituir um ambiente que pertença a todo tipo de usuário.

\subsection{Práticas inclusivas em bibliotecas}

Diante de todo o exposto em trabalhos e estudos desenvolvidos a respeito das bibliotecas e das pessoas com deficiência, alguns pontos em comum podem ser reunidos e sintetizados para o bibliotecário, para que novos estudos sejam gerados e atuações sejam repensadas e compartilhadas.

É preciso conhecer a pessoa com deficiência e suas reais necessidades, para que as práticas sejam planejadas e desenvolvidas em um ambiente acessível e compatível com as normas vigentes de acessibilidade, promovendo um espaço onde todos sejam incluídos: usuários reais, potenciais, comunidade, colaboradores e todo aquele que buscar informação.

É indispensável investir em sinalização visual nas bibliotecas (seja em Braille ou em Libras), bem como desenvolver acervos especiais e disponibilizar tecnologias que possam auxiliar na busca pela informação, respeitando a independência e autonomia de seus usuários.

Os recursos e equipamentos de Tecnologia Assistiva em si não representam inclusão, são as ações a partir dela que podem representar possibilidades reais para uma pessoa com deficiência. Portanto, é essencial conhecer sobre e verificar quais as melhores opções para atender aos usuários, compreender o que faz parte desse universo e como pode ser aproveitado da melhor forma.

As barreiras comunicacionais ou atitudinais no ambiente interno e externo das bibliotecas precisam ser superadas e/ou eliminadas. Não se pode pensar em inclusão sem rever antigos paradigmas a respeito da deficiência. $O$ ponto de partida para o desenvolvimento de produtos e serviços deve considerar a importância de ouvir os 
usuários e a comunidade em suas necessidades, críticas e sugestões.

Assim, ampliar os canais de informação, conscientizar a equipe e oferecer alertas sobre pesquisas, eventos, cursos gratuitos, reportagens a respeito da pessoa com deficiência para sua equipe, assim como é oferecido para usuários e comunidade em geral, pode ser uma opção viável e simples para todos. Quanto mais informação real circular entre o profissional e a equipe, maiores serão as probabilidades de proximidade com o usuário.

Outra medida de grande resultado é estabelecer parcerias com outros profissionais e com outras áreas, bem como se aproximar de seus pares, seja por grupos de estudo ou de discussão, para que ações sejam criadas e compartilhadas.

Especificamente para o bibliotecário, algumas medidas são indispensáveis, como: buscar atualizações constantes, desenvolver e/ou aprimorar competências profissionais, propor capacitações frequentes para suas equipes, aproveitar materiais adaptados e especiais em atividades que as bibliotecas já oferecem, como a hora do conto, rodas de conversa, orientações de pesquisa e consulta, eventos comemorativos, exposições, levantamento bibliográfico, alertas, etc. $\mathrm{O}$ fato de existir uma lacuna na formação não pode ser justificativa para a falta de ação diante das responsabilidades com a sociedade e com a diversidade de usuários.

\section{Conclusões}

É notória a contradição existente entre as necessidades da pessoa com deficiência e o que lhe é oferecido, no entanto, mais importante do que ter o que oferecer é saber para quem e como deve ser oferecido. O primeiro passo para um atendimento inclusivo, conforme apontado em diversos estudos discutidos ao longo deste texto, é conhecer o usuário com deficiência, só assim os produtos e serviços poderão ser oferecidos de forma significativa. Afinal, enquanto a pessoa com deficiência não se sentir parte do local, dificilmente vai frequentá-lo, conforme já descrito ao longo deste texto.

Os recursos e equipamentos da Tecnologia Assistiva estão mais presentes nas bibliotecas, o que não significa que estejam sendo utilizados de forma eficiente. Apenas ter o recurso não basta, assim como não basta falar de acesso como sinônimo de acessibilidade e pensar nela somente nos aspectos físicos. 
Diante de deficiências que exigem outras formas de comunicação, como a surdez, por exemplo, o bibliotecário precisa estar preparado para agir de forma rápida e não deixar que o usuário se sinta um "incômodo" naquele espaço. $\mathrm{O}$ conhecimento da língua de sinais (mesmo que seja básico) e de aplicativos ou softwares que possibilitem a comunicação pode representar um grande passo para que uma pessoa com deficiência se sinta acolhida.

Fica evidente que a falta de atitude perante os usuários com deficiência é uma das barreiras mais citadas pelos autores e talvez as menos trabalhadas, pois ainda há muita preocupação com as estruturas físicas, os acervos, os serviços e as tecnologias a serem utilizadas, deixando as barreiras da comunicação em segundo ou terceiro plano.

No período de recorte estabelecido para este artigo, as publicações a respeito das pessoas com deficiência e das bibliotecas não foram numerosas e suas datas são bem irregulares, dificultando uma continuidade na área a respeito da temática, mas, ainda assim, representam importantes contribuições a respeito da inclusão de um público que ainda é visto como um desafio para os profissionais da Biblioteconomia.

Esta pesquisa possibilitou conhecer não só a produção científica construída ao longo dos anos, como também constatar o quanto a Biblioteconomia e a Ciência da Informação precisam olhar para o usuário como ponto inicial para as suas ações. É a partir dele que tudo deve começar, e mesmo que ele não esteja ali, é preciso que o ambiente esteja preparado, pois não se pode esperar sua chegada para oferecer ou disponibilizar algo, isso definitivamente não está de acordo com os princípios da inclusão.

Discutir a formação em Biblioteconomia não foi o objetivo deste estudo, por isso não se aprofundou nas questões a respeito, embora tenha sido abordado por autores nos registros selecionados. Mas vale ressaltar que é de suma importância que os currículos sejam reformulados para atender melhor às demandas da área. É fato que as lacunas nas formações existem em todas as áreas e, ao constatá-las, é preciso que sejam minimizadas ou até eliminadas, com informação e conhecimento. Apenas discutir sobre as existências ou ausências não faz sentido diante da necessidade de inclusão e da responsabilidade social do bibliotecário, é preciso agir e modificar.

A base BRAPCI trouxe para a área da Ciência da Informação importantes 
possibilidades na reunião de conteúdo produzido por acadêmicos e profissionais, publicado em periódicos especializados, facilitando as consultas e as pesquisas ali realizadas, tornando-se uma referência de qualidade para estudantes e profissionais.

As propostas e as considerações registradas nos estudos analisados apontam um caminho em construção, que pode ser facilitado diante da atuação de profissionais que queiram diminuir a distância entre ele e o usuário. Bibliotecas inclusivas são viáveis diante de ações que favoreçam a todos.

Sabe-se que as bibliotecas enfrentam dificuldades em termos de espaço e estrutura e recursos, porém é preciso acompanhar, planejar e requisitar junto a instâncias superiores as modificações necessárias, pois a ausência delas pode comprometer a presença do usuário. A criatividade do profissional também se torna fundamental para que situações sejam compreendidas, evitadas e tratadas de forma adequada.

A capacitação profissional precisa ser mais frequente e envolver toda a equipe, pois as bibliotecas, não raramente, realizam o sistema de rodízio de funções/colaboradores e, diante disso, não se pode permitir que apenas um colaborador se capacite para atendimento a pessoa com deficiência.

A comunicação científica é outro ponto essencial para a atuação de profissionais, seja na participação em eventos ou em publicações da área, pois contribui para o compartilhamento de experiências e viabiliza ações que podem ser adotadas com êxito, independente das questões de tipologia das bibliotecas. Acreditase que os textos selecionados tenham em seus conteúdos muitos aspectos que podem contribuir para práticas bibliotecárias, por isso se sugere que sejam consultados e aproveitados em suas ações.

Não se trata de defender a figura de um "super" bibliotecário, capaz de saber sobre todas as formas de comunicação e de possuir todos os recursos, mas, sim, de um profissional que saiba atuar e buscar subsídios que possibilitem realizar seu trabalho de forma satisfatória para propiciar um ambiente de qualidade e inclusivo.

As perguntas iniciais apresentadas no início do texto foram respondidas ao mesmo tempo em que novas foram despertadas. É preciso que velhos paradigmas sejam eliminados para que a busca pela informação esteja ao alcance de todos. Somente assim a Biblioteconomia e a Ciência da Informação conseguirão cumprir seu 
papel social e sua responsabilidade diante de uma sociedade com equidade de oportunidades, acesso e acessibilidade para todos.

\section{Referências}

ARAUJO, E.M. et al. Princípios básicos da Língua Brasileira dos Sinais (Libras): uma experiência na biblioteca da EESC/USP. Revista Brasileira de

Biblioteconomia e Documentação, São Paulo, v. 13, n. esp. CBBD, 2017.

ASSIS, J.B.; DINIZ, C.N. Atendimento a pessoas com deficiência em bibliotecas universitárias. In: ENCONTRO NACIONAL DE PESQUISA EM CIÊNCIA DA INFORMAÇÃO, 18, ENANCIB, 2017. Anais [...]. Marilia: UNESP: ANCIB, 2017.

AVILA, R.M. et al. Quatro décadas de experiências em acessibilidade: o caso do Setor Braille da Biblioteca Pública do Estado da Bahia. In: SEMINÁRIO NACIONAL DE BIBLIOTECAS BRAILLE: cultura, educação e inclusão. 8, 2014. São Paulo. Anais [...]. São Paulo: FEBAB, 2014.

BARDIN, L. Análise de conteúdo. São Paulo: edições 70, 2016.

BAPTISTA, M.M.; GONÇALVES, M.S. Acessibilidade para colaboradores em bibliotecas universitárias: um estudo de caso no Sistema de Bibliotecas da Universidade de Caxias do Sul - SIBUCS. Revista ACB: Biblioteconomia em Santa Catarina, Florianópolis, n. esp., v.10, 2016.

BERSCH, R. Tecnologia Assistiva. Porto Alegre: Edição do autor, 2013.

BONILHA, F.F.G.; CARRASCO, C.R. O papel da biblioteca como espaço de disseminação da musicografia Braille: uso de ferramentas tecnológicas na produção de partituras para cegos. Revista ACB: Biblioteconomia em Santa Catarina, Florianópolis, v.13, n.1, p.18-25, jan./jun.2008.

BRASIL. Lei Brasileira de Inclusão da Pessoa com Deficiência (Estatuto da Pessoa com deficiência). Lei n. 13.146 de 6 de julho de 2015.

BUFREM, L.S. et al. Modelizando práticas para a socialização das informações: a construção de saberes no ensino superior. Perspectivas em Ciência da Informação, Belo Horizonte, v.15, n.2, 2010.

CARVALHO, A.; ALMEIDA, P. Direitos humanos e pessoas com deficiência: da exclusão a inclusão da promoção. Revista Internacional de Direitos e Cidadania, João Pessoa, n.12, fev. 2012.

CAVALCANTE, C.O.P.; GARCIA, R.I.; RADOS, G.J.V. Acessibilidade física na biblioteca do Instituto Federal de Educação, Ciência e Tecnologia de Santa Catarina, Campus Araranguá. Revista ACB: Biblioteconomia em Santa Catarina, Florianópolis, n.3, v. 20, p. 483-499, 2015.

CONEGLIAN, A.L.O.; CASARIN, H.C.S. Deficientes como usuários de informação. 
In: CASARIN, H.C.S. Estudos de usuários da informação. Brasília: Thesaurus, 2014.

COSTA, M. M.; SILVA, M.A.T. Uma análise da acessibilidade para deficientes visuais na Seção Braille da Biblioteca Central da UFPB. Biblionline, [s.l.], v.15, n.2, p.79-95, 2019.

COSTA, M.K.A.; DUARTE, A.B.S. A (in) acessibilidade nas bibliotecas universitárias: a interação entre o bibliotecário de referência e o usuário com deficiência. Revista Brasileira de Biblioteconomia e Documentação, São Paulo, v.13, n.2, jul./dez. 2017.

CUNHA, M.B. Desafios na construção de uma biblioteca digital. Ciência da Informação, Brasília, v.28, n.3, p.257-268, set./dez. 1999.

DIAS, M.R.; BON, G. Um olhar ao estudante com surdez da Universidade Federal do Rio Grande do Norte: análise sobre a acessibilidade à informação na Biblioteca Central Zila Mamede. BiblioCanto, Natal, v.5, n.1, p. 83-104, 2019.

DINIZ, C.N. et al. Acessibilidade em biblioteca escolar: estudo de caso do Instituto Federal do Rio de Janeiro, Campus Paracambi-RJ. Informação em Pauta, Fortaleza, v.2, n. esp., out. 2017.

DINIZ, I.C.S.; ALMEIDA, A.M.; FURTADO, C. Bibliotecas universitárias inclusivas: acessibilidade e oportunidades para usuários com necessidades especiais. Revista Brasileira de Biblioteconomia e Documentação, São Paulo, v.13, n.esp. 2017a..

DINIZ, I.C.S.; ALMEIDA, A.M.; FURTADO, C.C. Os desafios e as barreiras das bibliotecas universitárias brasileiras e portuguesas o processo de inclusão e acessibilidade. Páginas A\&B: Arquivos e Bibliotecas, [s.l.], série 3, n.esp., p. 53-74, $2017 b$.

FARMER, L.S. Library services for your with Autism Spectrum Disorders. Chicago: ALA Editions, 2013.

FERNANDES, N.L.; VIANNA, W.B. Percepção de deficientes visuais quanto à Tecnologia Assistiva e os softwares de síntese de voz para uso em bibliotecas. Pesquisa Brasileira em Ciência da Informação e Biblioteconomia, João Pessoa, v.11, n.2, p. 1-8, 2016.

FERREIRA, A.F.B.C. Biblioteca Louis Braille do Instituto Benjamin Constant: assegurando ao deficiente visual acesso ao conhecimento. Revista ACB:

Biblioteconomia em Santa Catarina, Florianópolis, v.13, n.1, p. 282-290, jan./jun. 2008.

FERREIRA, R.R.; CHAGAS, K.R. O bibliotecário como mediador no processo de inclusão do surdo em bibliotecas universitárias. Revista Bibliomar, São Luís, v.15, 
n.1/2, jan./jun. 2016.

FERREIRA, A.F.B.C.; OLIVEIRA, M.I.S.; PINTO, M.C. Biblioteca Louis Braille: os olhos para aquele que não vê. Arquivistica.net, [s.l.], v.1, n.2, 2006.

FIALHO, J.F. Informação e conhecimento acessíveis aos deficientes visuais nas bibliotecas universitárias. Perspectivas em Ciência da Informação, Belo Horizonte, v. 17, n. 1, p. 153-168, 2012.

FIALHO, J.; SILVA, D.O. Informação e conhecimento acessíveis aos deficientes visuais nas bibliotecas universitárias. Perspectivas em Ciência da Informação, Belo Horizonte, v. 17, n. 1, p. 153-168, jan./jun.2012.

GUERREIRO, E.M.B.R. et al. Acessibilidade na biblioteca do IFAM/Campus Manaus Centro. Revista ACB: Biblioteconomia em Santa Catarina, Florianópolis, v. 20, n. 2, p. 321-338, maio/ago. 2015.

GIACUMUZZI, G.; MORO, E.L.S. Acessibilidade arquitetônica em diferentes tipologias de bibliotecas. In: SEMINÁRIO NACIONAL DE BIBLIOTECAS BRAILLE: cultura, educação e inclusão. 8, 2014. São Paulo. Anais [...]. São Paulo: FEBAB, 2014.

JACINTO, S.O. A biblioteca pública e os deficientes físicos. Revista Brasileira de Biblioteconomia e Documentação, São Paulo, v. 2, n. 4, p. 89-104, 2008.

INSTITUTO BRASILEIRO DE GEOGRAFIA E ESTATÍSTICA. Censo Demográfico 2010: características gerais da população, religião e pessoas com deficiencia. Rio de Janeiro, 2010.

LEIVA, I.G.; FUJITA, M.S.L. Política de indexação. São Paulo: Cultura Acadêmica; Marilia: Oficina universitária, 2012.

MAIOR, I.M.M.L. Movimento político das pessoas com deficiencia: reflexões sobre a conquista de direitos. Ciência da Informação, Brasília, v. 10, n. 2, p.28-36, jan./jun. 2017.

MALHEIROS, T.M.; CUNHA, M.B. As bibliotecas como facilitadoras no acesso à informação por usuários com deficiência visual. RBBCI: Revista Digital de Biblioteconomia e Ciência da Informação, Campinas, v. 16, n. 1, p.146-170, jan/jun. 2018.

MANZINI, E.J. Inclusão e acessibilidade. Revista Sobama, São Paulo, v. 10, n. 1, p. 31-36, 2005.

MANZINI, E. J. Considerações teóricas sobre acessibilidade: da definição às concepções atuais. In: MANZINI, E. J.; CORRÊA, P. M. (org.). Avaliação de acessibilidade na educação infantil e no ensino superior. Marília: ABPEE; São Carlos: Marquezine \& Manzini editora, 2014. 
MANZINI, E.J.; GERMANO, G.D.; OLIVEIRA, G.D. (org.). Política de e para Educação Especial. Marilia: ABPEE, 2018.

MATOS, E.J.S.; LEMOS, R.B.S.; SILVA, J.L. As Tecnologias Assistivas para a educação na biblioteca pública Benedito Leite. Revista Bibliomar, São Luís, v.16, n.1, p. 36-51, jan./jun., 2017.

MELO, A.M.; COSTA, J.B.; SOARES, S.C.M. Tecnologias Assistivas. In: PUPO, D.T.; MELO, A.M.; FERRES, S.P. (org.). Acessibilidade: discurso e prática no cotidiano das bibliotecas. Campinas: UNICAMP, 2006.

MIGLIOLI, S.; SANTOS, G.A. Acessibilidade e serviços inclusivos para minorias sociais: a Biblioteca do Instituto Nacional de Surdos. Revista ACB: Biblioteconomia em Santa Catarina, Florianópolis, v. 22, n. 1, p. 136-149, dez./mar. 2017.

MILANESI, L. Biblioteca pública: do século XIX para o XXI. Revista USP, São Paulo, n. 97, p. 59-70, mar. 2013.

MIRANDA, S.N.; MIRANDA, M.L.C. Bibliotecas universitárias e a acessibilidade aos usuários surdos e com deficiencia auditiva. Informação @Profissões, Londrina, n. 2, v. 4, p. 4-19, 2015.

MIRANDA, S.N. Comunicação acessível aos usuários surdos e com deficiência auditiva em bibliotecas: uma análise das normas brasileiras. Revista Brasileira de Biblioteconomia e Documentação, São Paulo, v.13, 2017.

MIRANDA, S. N.; COSTA, M. V. S. B.; SILVA, M. M. O usuário surdo e a acessibilidade no sistema de bibliotecas da UNIRIO. Revista Brasileira de Biblioteconomia e Documentação, São Paulo, v. 13, n. 2017, p. 2008-2019, 2019.

MIRANDA, L.A. Arte, memória, informação e deficiência: as bibliotecas de arte e a democratização dos saberes. Revista Brasileira de Biblioteconomia e Documentação, v.15, n.esp. p. 294-313, 2019. Disponível em:

https://rbbd.febab.org.br/rbbd/article/view/1369/1186 Acesso em: 25 jun. 2020.

MORAES, L.S. Espaço Braille: leitura e informação para a cidadania. Revista ACB: Biblioteconomia em Santa Catarina, Florianópolis, v. 13, n. 1, p. 251-258, jan/jun. 2008.

NOVO, A. "Projeto Acessibilidades" em 15 bibliotecas municipais de Lisboa: principais conclusões. Cadernos BAD, Lisboa, n. 1, p. 163-176, jan./jun. 2015.

OLIVEIRA, G. D.; SILVA, E.F. Bibliotecas e bibliotecários em busca da acessibilidade. BiblioCanto, Natal, v. 1, n. 1, p. 68-86, 2015.

OLIVEIRA, R.M. Biblioteca universitária: leitura inclusiva através do audiocordel.

BiblioCanto, Natal, v. 1, n. 1, p. 2-15, 2015. 
ORRICO, M.A.; SILVA, A.P. Rede de leitura inclusiva. 2014.

OTTONI, B.L. et al. Abordagem ao usuário com deficiência visual na Rede de Bibliotecas da UNESP. In: SEMINÁRIO NACIONAL DE BIBLIOTECAS BRAILLE: cultura, educação e inclusão, 8, 2014. São Paulo. Anais [...] São Paulo: FEBAB, 2014.

PINHEIRO, D.S. O bibliotecário e o usuário especial em unidades de informação: formação e realidade profissional. 2004. 146f. Trabalho de Conclusão de Curso em Biblioteconomia. Faculdade de Filosofia e Ciências. Universidade Estadual Paulista, Marília, SP.

PINHEIRO, M.I.S.; SILVA, E.R.P.; RODRIGUES, L.R.Q. O ir e vir dos deficientes visuais: barreiras arquitetônicas e acadêmicas na UFMT. Inclusão Social, Brasília, v. 3, n. 1, p. 48-65, out./mar. 2008.

PINHEIRO, A. L.; OLIVEIRA, H. V. Tecnologia assistiva no processo de mediação da informação aos usuários com deficiência visual em biblioteca universitária. In: ENCONTRO NACIONAL DE PESQUISA EM CIÊNCIA DA INFORMAÇÃO, 19, 2018. Anais [...]. ENANCIB: 2018.

PUPO, D.T. et al. Tecnologias Assistivas. Campinas: UNICAMP, 2008.

PUPO, D.T.; CARVALHO, S.H.R.; OLIVEIRA, V.C. Educação inclusiva e bibliotecas acessíveis. Revista ACB: Biblioteconomia em Santa Catarina, Florianópolis, v. 13, n. 1, p. 59-267, jan./jun. 2008.

RAMALHO, F.A.; HAMAD, H. GUIMARAES, I.J.B. Comportamento informacional dos discentes deficientes visuais da Universidade Federal da Paraíba UFPB. Informação \& Informação, Londrina, n. 1, v. 21, p. 230-256, 2016.

RODRIGUES, T.A.; FUJITA, M.S.L.; DAL'EVEDOVE, P.R. Política de indexação em bibliotecas destinadas às necessidades dos usuários deficientes visuais. Revista Conhecimento em ação, Rio de Janeiro, n. 2, v. 2, p. 56-72, 2017.

ROMA, I.A. A.; CAVALCANTE, L. F.B. Acessibilidade nas bibliotecas escolares estaduais de Londrina. Revista Brasileira de Biblioteconomia e Documentação, São Paulo, n. 1, v. 14, p. 167-186, 2018.

SANTOS, K.G.; CARVALHO, K.A. Acessibilidade e tecnologia assistiva em bibliotecas universitárias: estudo de caso no CEFET-MG. RICI, Brasília, v. 13, n. 1, p. 5-19, jan./abr. 2020.

SANTOS, M.P.; DINIZ, C.N.; FERNANDES, E.M. Acessibilidade informacional para usuários com transtorno de Espectro Autista na biblioteca. Revista Brasileira de Biblioteconomia e Documentação, São Paulo, v. 13, p. 1863-1882, 2017. 
SANTOS, M.P.; DINIZ, C.N.; RANGNI, R.A. Pessoas surdocegas em bibliotecas: discussões iniciais. Revista Brasileira de Biblioteconomia e Documentação, São Paulo, v. 13, p. 2051-2064, 2017.

SAMPAIO, M.I.C. Acessibilidade do espaço físico da Biblioteca Dante Moreira Leite. Revista Brasileira de Biblioteconomia e Documentação, São Paulo, n.esp., v. 0, 2014.

SILVA, R.A.; SANTOS, R.N.N.; RODRIGUES, R.S. Estudo bibliométrico na base LISA: um enfoque nos artigos sobre os surdos. Em Questão, Porto Alegre, v. 17, p. 390-2402, 2017.

SOUZA, S.C.; MANOEL, V.A. Praticando acessibilidade comunicacional: cooperação entre biblioteca universitária e programa de promoção de acessibilidade. Revista ACB: Biblioteconomia em Santa Catarina, Florianópolis, v. 13, n. 1, p. 7-17, jan./jun. 2008.

STORTI, V.R. et al. Promover a acessibilidade aos deficientes visuais e baixa visão à Rede de Bibliotecas da UNESP. In: SEMINÁRIO NACIONAL DE BIBLIOTECAS BRAILLE: cultura, educação e inclusão. 8, 2014. São Paulo. Anais [...] São Paulo: FEBAB, 2014.

TABOSA, H.R.; PEREIRA, V.G. Estudo sobre a qualificação do bibliotecário cearense para o atendimento de usuários com deficiência visual. RACIn, João Pessoa, v. 1, n. 2, p. 21-36, jul./dez. 2013.

VENTURA, L.; VIANNA, W.B.; BEDIN, J. A tecnologia assistiva como apoiadora no processo de ensino-aprendizagem de crianças com deficiência intelectual: contribuições da literatura. Pesquisa Brasileira em Ciência da Informação, João Pessoa, v. 12, n. 2, p. 270-292, 2017.

VIANNA, W.B.; PINTO, A.L. Deficiência, acessibilidade e tecnologia assistiva em bibliotecas: aspectos bibliométricos relevantes. Perspectivas em Ciência da Informação, Belo Horizonte, v. 22, n. 2, p. 125-151, abr./jun. 2017.

VIEIRA, L.C.B. Biblioteca inclusiva: repensando políticas de acesso e inclusão para deficientes auditivos na Universidade Federal do Maranhão. Biblionline, João Pessoa, v. 10, n. 1, p. 82-101, 2014.

WELLICHAN, D.S.P.; SOUZA, C.S. A inclusão na prática: alunos com deficiência no Ensino Superior. Revista on-line de Política e Gestão Educacional, Araraquara, v. 21, n. 1, p. 146-166, 2017.

WELLICHAN, D.S.P.; LINO, C.C.T.S. A biblioteca escolar no contexto da inclusão: como oferecer e vivenciar experiências inclusivas nesse ambiente. Biblionline, João Pessoa, v. 14, n. 1, p. 3-16, 2018.

WELLICHAN, D.S.P.; MANZINI, E.J. A Tecnologia Assistiva em bibliotecas públicas: uma abordagem preliminar sobre sua importância e contribuição para 

análise da produção científica em Biblioteconomia e Ciência

usuários com deficiência. Biblionline, João Pessoa, v. 14, n. 4, p. 83-90, 2018.

\title{
Disabled information users in libraries: an analysis of scientific production in
}

\section{Librarianship and Information Science}

\begin{abstract}
Users with disabilities are still unknown and pose important challenges for library practice. Therefore, analyzing the existence of this user in the context of information is a necessity to rethink the relevance of our information environments. Thus, in order to analyze how the person with disabilities, as a user of information, was approached by the literature in the area in the period from the 1970 s to 2019, we sought to carry out a bibliographic survey in a database in the area of Science Information. Specific descriptors were used and the results were analyzed and categorized considering variables such as studies aimed at: 1) accessibility and inclusion; 2) Assistive Technology in libraries; 3) deficiencies more and less addressed; 4) aspects regarding professional performance; 5) inclusive practices existing in libraries. Although the literature presents significant studies and that the libraries mostly have Assistive Technology resources, the area requires attention, reflection and action in view of the real needs of a user with a disability, for a more meaningful performance that provides, from the ideal inclusion, a possible reality in the informational environment.
\end{abstract}

Keywords: Information user. Disabled people. Assistive Technology. Accessibility. Libraries.

\section{Declaração de autoria}

Concepção e elaboração do estudo: Wellichan, D.S.P.; Manzini, E.J.

Coleta de dados: Wellichan, D.S.P.; Manzini, E.J.

Análise e interpretação de dados: Wellichan, D.S.P.; Manzini, E.J.

Redação: Wellichan, D.S.P.; Manzini, E.J.

Revisão crítica do manuscrito: Wellichan, D.S.P.; Manzini, E.J.

\section{Como citar}

WELLICHAN, Danielle Silva Pinheiro; MANZINI, Eduardo José. Usuários da informação com deficiência em bibliotecas: uma análise da produção científica em Biblioteconomia e Ciência da Informação. Em Questão, Porto Alegre, , v. 27, n. 3, p. 172-203, 2021. Doi: http://dx.doi.org/10.19132/1808-5245273.172-203 

análise da produção científica em Biblioteconomia e Ciência da Informação

Danielle Silva Pinheiro Wellichan e Eduardo José Manzini

${ }^{1}$ A título de informação: os autores e seus estudos não necessariamente surgiram em ordem cronológica devido à construção do texto.

${ }^{2}$ OMOTE, S. Entrevista concedida para coleta de dados de trabalho de conclusão de curso. 2004. In: PINHEIRO, D.S. O bibliotecário e o usuário especial em unidades de informação: formação e realidade profissional. 2004. 146f. Trabalho de Conclusão de Curso em Biblioteconomia. Faculdade de Filosofia e Ciências. Universidade Estadual Paulista, Marília, SP. Apud Pinheiro 2004. 